\title{
A MOTIVAÇÃO DO HOMEM PARA O TRABALHO: UM ESTUDO SOBRE O IMPACTO DA CRISE ECONÔMICA MUNDIAL
}

\author{
THE MOTIVATION OF MAN TO WORK: IMPACT OF \\ THE GLOBAL ECONOMIC CRISIS STUDY
}

\author{
Recebido 25/10/2012 \\ Aceito $21 / 01 / 2013$ \\ Felipe Carvalho Fongaro Nars ${ }^{1}$ \\ Marcos Aurélio de Almeida Ferreira ${ }^{2}$ \\ André Luiz Fischer ${ }^{3}$
}

\section{RESUMO}

O objetivo geral desta pesquisa foi identificar diferenças significativas nos níveis de "Satisfação e Motivação" entre funcionários das "Melhores Empresas para se Trabalhar no Brasil", eleitas pelo Guia Você S/A-Exame, no período de 2007 a 2009. Os objetivos específicos procuraram: (1) verificar se o resultado da categoria "Satisfação e Motivação" de 2009 difere significativamente de 2007 e 2008; (2) verificar as variações nos índices que compõem o resultado desta categoria em 2009 e relacioná-las com a teoria sobre motivação; e (3) identificar no discurso dos funcionários elementos que evidenciem as ações tomadas pelas empresas perante a crise econômica mundial em 2009 para mantê-los motivados e relacionar tais ações com a teoria sobre gestão na era da turbulência econômica. O referencial teórico abordou três temas principais: (1) o clima organizacional - sua relação com o sistema organizacional e a motivação, a importância da sua medição através de pesquisas de clima organizacional estruturada por categorias e as ações da alta administração decorrentes de seus resultados; (2) a motivação - um resgate conceitual do tema e a recente discussão sobre o sentido atribuído ao trabalho como fonte de motivação; e (3) a gestão na era da turbulência econômica - a atuação da liderança frente aos novos desafios de gestão em meio ao caos e a comunicação clara e eficaz necessária para manutenção do moral da equipe em períodos de crise. A fim de encontrar as respostas ao problema proposto, foi realizada uma pesquisa descritiva, com enfoque na análise de dados quantitativa e qualitativa. A amostra da pesquisa foi composta pelas 66 empresas que figuraram consecutivamente nos Guias de 2007, 2008 e 2009. A análise estatística deu-se pela aplicação do teste Kolmogorov-Smirnov (KS), pelo Modelo Linear Geral (GLM) e pelo método de seleção Lambda de Wilks. Os resultados quantitativos, alcançados pela aplicação de testes de hipóteses e testes de comparação entre médias, demonstraram queda nos níveis de "Satisfação e Motivação" em 2009 em relação ao ano de 2007 e 2008. A partir dessa descoberta, foram aplicados dois métodos de análise qualitativa (análise exploratória dos dados e análise de enunciação), a fim de verificar a possível influência da crise

\footnotetext{
${ }^{1}$ Possui graduação em Engenharia da Produção pela Fundação Instituto de Administração - FIA e especialização em Modelos de Gestão Estratégica de Pessoas pela Fundação Instituto de Administração - FIA. Atualmente é Coordenador de Projeto na Prime Action Consulting. São Paulo, São Paulo, Brasil. E-mail: felipenars@terra.com.br.

2 Possui graduação em Administração de Empresas e pós-graduação em Administração Financeira pela Universidade do Vale dos Sinos - UNISINOS, MBA em Negócios pela BSP e Universidade de Toronto, mestrado e doutorado pela Universidade de São Paulo USP. São Paulo, São Paulo, Brasil. E-mail: maaferreira@usp.br.

${ }^{3}$ Possui graduação em Ciências Políticas e Sociais pela Fundação Escola de Sociologia e Política de São Paulo - FESPSP, mestrado em Ciências Sociais pela Pontifícia Universidade Católica de São Paulo - PUC/SP e doutorado em Administração de Empresas pela Faculdade de Economia Administração e Contabilidade da Universidade de São Paulo. Atualmente é professor e pesquisador da Faculdade Economia Administração e Contabilidade da Universidade de São Paulo. São Paulo, São Paulo, Brasil. E-mail: afischer@usp.br.
} 
econômica mundial nesses níveis. Os resultados qualitativos mostraram sete pontos de atenção, dos quais cinco apresentaram variação negativa entre 2008 e 2009 e somente dois apresentaram variação positiva nesse menos período. Além desses pontos, a análise qualitativa permitiu identificar no discurso dos funcionários algumas ações tomadas pelas empresas com relação à liderança, comunicação e manutenção do moral, corroborando o referencial teórico apresentado. As conclusões deste estudo apontaram para a queda dos níveis de "Satisfação e Motivação" em 2009 e para o esforço das empresas em realizarem uma gestão voltada para a superação da crise. Algumas recomendações práticas são apresentadas à comunidade de RH para serem aplicadas em épocas de turbulência econômica a fim de mitigar os possíveis impactos negativos explicitados por esta pesquisa.

Palavras-chave: Motivação, trabalho, crises, economia mundial.

\section{ABSTRACT}

The general objective of this research is to identify significant differences in the levels of 'Satisfaction and Motivation' among employees of the Best Companies to Work For in Brazil, elected by Guia Você S/A-Exame, between 2007 and 2009. The specific objectives seek to: (1) verify if the result of the category 'Satisfaction and Motivation' in 2009 differs significantly from 2007 and 2008, (2) assess the variations in the indices that composes the result of this category in 2009 and relate them to the theory of motivation, and (3) identify elements in the speech of employees that demonstrate the actions taken by companies before the global economic crisis in 2009 to keep them motivated and relate them to the theory of management in the era of economic turbulence. The theoretical framework addresses three main issues: (1) organizational climate - its relationship to the organizational system and motivation, the importance of its measurement through organizational climate surveys structured by categories and actions of senior management due to its results. (2) Motivation - a conceptual overview and the recent discussion about the meaning assigned to work as a source of motivation. (3) The management in the era of economic turbulence - the role of leadership dealing with new challenges of management in the chaos, clarity and effectiveness communication due to maintain team morale in times of crisis. In order to find the answers to the proposed problem, we performed a descriptive analysis with focus on quantitative and qualitative data. The survey sample was comprised of 66 companies that figured in the Guides for 2007, 2008 and 2009. The Statistical analysis was given by applying the Kolmogorov-Smirnov (KS) test, additionally the General Linear Model (GLM) and the selection method of Wilks Lambda. The quantitative results obtained by applying hypothesis and comparison tests between means showed a drop in the levels of 'Satisfaction and Motivation' in 2009 compared to 2007 and 2008. From this result, we applied two methods of qualitative analysis (exploratory data analysis and discourse analysis), in order to verify the possible influence of global economic crisis on this result. Qualitative results show seven points of attention, five of which had higher negative change between 2008 and 2009 and only two showed positive growth between 2008 and 2009. In addition to these points of attention, the qualitative analysis according to the speech of employees identified some actions taken by companies about leadership, communication and maintenance of morale, corroborating the theory presented. The study's findings point to the falling levels of 'Satisfaction and Motivation' in 2009 and the efforts of management focused on overcoming the crisis. Some practical recommendations are submitted to the HR community, so that in times of economic turbulence they might be applied in order to mitigate potential negative impacts explained by research.

Keywords: Motivation, work, crisis, world economy. 


\section{INTRODUÇÃO}

O capítulo 1 apresenta a contextualização, a justificativa e a matriz de amarração deste estudo. 0 capítulo 2 aborda o referencial teórico, que está subdividido em três seções: (1) clima organizacional, (2) motivação e (3) gestão na era da turbulência econômica. 0 capítulo 3 aborda a metodologia de pesquisa. $O$ capítulo 4 apresenta o plano de análise de dados. $O$ capítulo 5 é dedicado à análise dos resultados. E, por fim, o capítulo 6 discute as considerações finais desta pesquisa.

\subsection{Contextualização}

A economia mundial foi fortemente abalada no último trimestre de 2008 , quando irrompeu nos Estados Unidos a crise no mercado subprime. Ao detectarem indícios de crise e reconhecerem as implicações que a queda da atividade poderia exercer sobre a economia real, os bancos centrais dos países desenvolvidos coordenaram ações com o objetivo de estabilizar seus sistemas financeiros e diminuir os efeitos sobre o nível de atividade. Nesse contexto, o Brasil registrou dois períodos distintos em 2008. Nos primeiros três trimestres do ano, o aumento do consumo e do investimento privado puxou o crescimento econômico. No último trimestre, os impactos da crise econômica internacional foram sentidos pela dificuldade na obtenção de crédito e pelas expectativas dos agentes econômicos (Banco Central do Brasil [Bacen], 2009).

A Figura 1 demonstra o crescimento constante do Produto Interno Bruto (PIB) do Brasil entre o primeiro trimestre de 2007 e o terceiro trimestre de 2008. Já a Figura 2 demonstra que, a partir do terceiro trimestre de 2009 , houve diminuição no nível de contratações no mercado formal.

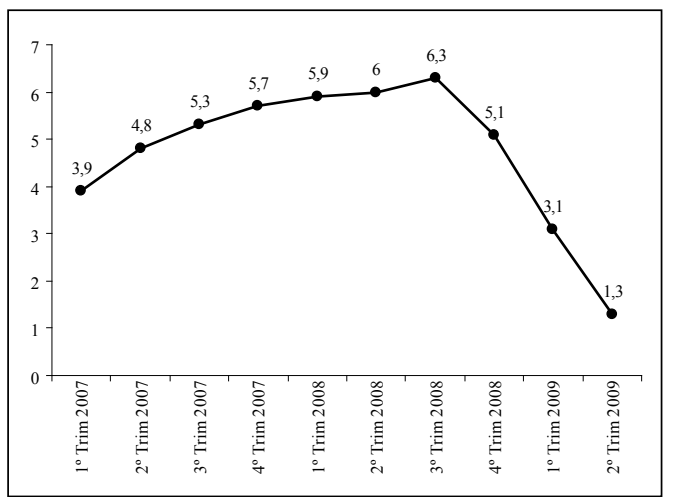

Figura 1 - PIB a preços de mercado - Taxa (\%) de crescimento acumulada em quatro trimestres Fonte: adaptado do Instituto Brasileiro de Geografia e Estatística [IBGE], 2009.

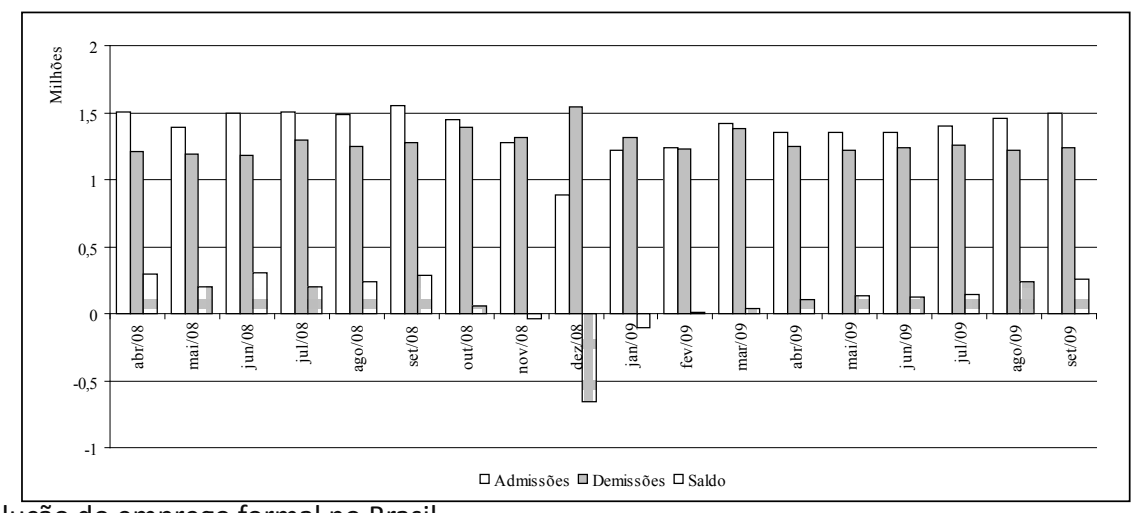

Figura 2 - Evolução do emprego formal no Brasil

Fonte: adaptado do Cadastro Geral de Empregados e Desempregados [CAGED], 2009. 
Diante desse fenômeno, Gaulejac (2007) afirma que, atualmente, os recursos humanos passaram a ser considerados uma variável de ajuste, flexibilizada ao máximo, a fim de atender as exigências do mercado. "Adaptabilidade, flexibilidade, reatividade tornam-se as palavras de ordem de um 'bom' gerenciamento de recursos humanos" (Gaulejac, 2007, p. 41). A esse respeito, Gorz (2007), que define a ideologia dos recursos humanos como aquela que transformou as empresas em um local de integração social e desenvolvimento profissional, afirma que aspectos como o clima da empresa, a satisfação no trabalho e a qualidade das relações sociais de cooperação, que não dizem respeito à racionalidade econômica, influenciam na eficácia no e desempenho dos trabalhadores.

Bergamini (2006) complementa a visão de Gaulejac (2007) e Gorz (2007) ao propor que o entendimento da motivação para o trabalho deve abranger todos os aspectos que compõem a situação organizacional: o indivíduo, o trabalho e a organização. Litwin e Stringer (1968 como citado em Nardi, 2004) aprofundam essa visão ao incorporarem, em seu "modelo subjetivo dos determinantes do comportamento motivado nas organizações", o relacionamento do ambiente externo às limitações organizacionais (tecnologia, liderança, regras, suposições, políticas e estrutura), interpondo os grupos de expectativas e incentivos entre o clima organizacional e a motivação despertada.

\subsection{Justificativa}

A relevância deste trabalho dá-se em decorrência da lacuna existente nos estudos que abordam a influência de variáveis ambientais na Gestão Estratégica de Pessoas. Ao explorar os possíveis impactos das turbulências do ambiente econômico na satisfação e motivação dos funcionários, as empresas podem gerar políticas e estratégias mais consistentes para a Gestão Estratégica de Pessoas.

\subsection{Problema de Pesquisa, Hipóteses e Objetivos}

\begin{tabular}{|c|c|c|c|c|}
\hline $\begin{array}{l}\text { Problema de } \\
\text { Pesquisa: }\end{array}$ & \multicolumn{4}{|c|}{$\begin{array}{l}\text { Há diferenças significativas nos níveis de "Satisfação e Motivação" dos funcionários das } \\
\text { Melhores Empresas para se Trabalhar no Brasil entre } 2007 \text { e 2009? }\end{array}$} \\
\hline \multirow{2}{*}{\multicolumn{5}{|c|}{$\begin{array}{l}\text { HO: Não há diferença entre as médias dos três anos }(2007,2008,2009) \\
\text { H1: Há diferenca entre as médias de pelo menos dois dos três anos. }\end{array}$}} \\
\hline & & & & \\
\hline \multicolumn{2}{|c|}{ Objetivo de Pesquisa } & $\begin{array}{l}\text { Fundamentação } \\
\text { Teórica }\end{array}$ & $\begin{array}{l}\text { Técnicas de Aná- } \\
\text { lise de Dados }\end{array}$ & $\begin{array}{l}\text { Resultado } \\
\text { Esperado }\end{array}$ \\
\hline \multirow{3}{*}{$\begin{array}{l}\text { Identificar } \\
\text { diferenças } \\
\text { significativas } \\
\text { nos níveis de } \\
\text { "Satisfação e } \\
\text { Motivação" } \\
\text { dos funcio- } \\
\text { nários das } \\
\text { Melhores Em- } \\
\text { presas para se } \\
\text { Trabalhar no } \\
\text { Brasil entre } \\
2007 \text { e } 2009 \text {. }\end{array}$} & $\begin{array}{l}\text { Verificar se os níveis de "Satisfa- } \\
\text { ção e Motivação" dos funcioná- } \\
\text { rios das Melhores Empresas para } \\
\text { se Trabalhar no Brasil em } 2009 \\
\text { difere significativamente de } 2007 \\
\text { e } 2008 \text {. }\end{array}$ & $\begin{array}{l}\text { 1) Clima Organiza- } \\
\text { cional } \\
\text { 2) Motivação } \\
\text { 3) Gestão na era } \\
\text { da turbulência } \\
\text { econômica }\end{array}$ & $\begin{array}{l}\text { Análise Quanti- } \\
\text { tativa: } \\
\text { Teste de pares } \\
\text { de médias (pos- } \\
\text { t-hoc LSD). }\end{array}$ & $\begin{array}{l}\text { Diferença } \\
\text { da média de } \\
2009 \text { em rela- } \\
\text { ção a } 2007 \text { e } \\
2008 .\end{array}$ \\
\hline & $\begin{array}{l}\text { Verificar as variações nos índices } \\
\text { que compõem o resultado da ca- } \\
\text { tegoria "Satisfação e Motivação" } \\
\text { da Pesquisa de Clima Organizacio- } \\
\text { nal das Melhores Empresas para } \\
\text { se Trabalhar no Brasil em } 2009 \text { e } \\
\text { relacionar tais variações com a } \\
\text { teoria sobre motivação. }\end{array}$ & $\begin{array}{l}\text { 1) Clima Organiza- } \\
\text { cional } \\
\text { 2) Motivação }\end{array}$ & $\begin{array}{l}\text { Análise Qualita- } \\
\text { tiva: } \\
\text { Análise explora- } \\
\text { tória de dados. }\end{array}$ & \begin{tabular}{|l} 
Variação \\
negativa \\
nos índices, \\
identificação \\
de pontos \\
de atenção e \\
relação com a \\
teoria. \\
\end{tabular} \\
\hline & $\begin{array}{l}\text { Identificar no discurso dos fun- } \\
\text { cionários das Melhores Empresas } \\
\text { para se Trabalhar no Brasil ele- } \\
\text { mentos que evidenciem as ações } \\
\text { tomadas pelas empresas perante } \\
\text { a crise econômica mundial em } \\
2009 \text { para mantê-los motivados e } \\
\text { relacionar tais ações com a teoria } \\
\text { sobre gestão na era da turbulên- } \\
\text { cia econômica. }\end{array}$ & $\begin{array}{l}\text { 1) Gestão na era } \\
\text { da turbulência } \\
\text { econômica } \\
\text { 2) Motivação }\end{array}$ & $\begin{array}{l}\text { Análise Qualita- } \\
\text { tiva: Análise de } \\
\text { Enunciação. }\end{array}$ & $\begin{array}{l}\text { Presença de } \\
\text { elementos } \\
\text { no discurso e } \\
\text { relação com a } \\
\text { teoria. }\end{array}$ \\
\hline
\end{tabular}

Figura 3 - Matriz de Amarração

Fonte: elaborado pelos autores (2012). 


\section{REFERENCIAL TEÓRICO}

Neste capítulo, são abordados os principais aspectos do clima organizacional e da motivação do homem para o trabalho. Também é apresentado um breve resumo sobre o ambiente empresarial contemporâneo, com o objetivo de sustentar as análises e conclusões deste trabalho.

\subsection{Clima Organizacional}

O clima organizacional, segundo Litwin e Stringer (1968 como citado em Nardi, 2004), representa uma relação entre o sistema organizacional e a motivação e é operacionalizado pela soma das percepções dos indivíduos que trabalham na organização. Ao integrarem o conceito de clima organizacional nas teorias de comportamento organizacional, os autores propuseram o modelo exposto na Figura 4.

\begin{tabular}{|c|c|c|c|c|}
\hline $\begin{array}{c}\text { Sistema Organizacional } \\
\text { Tecnologia }\end{array}$ & $\begin{array}{l}\text { Ambiente } \\
\text { Organizacional } \\
\text { Percebi do }\end{array}$ & $\begin{array}{r}\text { Motivação } \\
\text { Provocada }\end{array}$ & $\begin{array}{l}\text { Comportamento } \\
\text { Emergente }\end{array}$ & $\begin{array}{c}\text { Conseqüêências } \\
\text { Para a } \\
\text { Organização }\end{array}$ \\
\hline $\begin{array}{l}\text { Estrutura Organizacional } \\
\text { Estrutura Social } \\
\text { Liderança } \\
\text { Suposições e Práticas } \\
\text { Admin istrativas } \\
\text { Processo de Tomada de } \\
\text { Decisão } \\
\text { Necessidade dos }\end{array}$ & $\begin{array}{l}\text { Dimensões do clima } \\
\text { organizacional (ou } \\
\text { expectativas de papéis } \\
\text { estabelecidos) }\end{array}$ & $\begin{array}{l}\text { Realização } \\
\text { Afiliação } \\
\text { Poder } \\
\text { Agressão } \\
\text { Medo }\end{array}$ & $\begin{array}{l}\text { Atividades } \\
\text { Interações } \\
\text { Sentimentos }\end{array}$ & $\begin{array}{l}\text { Produtividade } \\
\text { Satisfação } \\
\text { Retenção } \\
\text { (turn over) } \\
\text { Inovação } \\
\text { Adaptabilidade } \\
\text { Reputação } \\
\text { (imagem) }\end{array}$ \\
\hline Membros & & \multicolumn{2}{|c|}{ feedback } & \\
\hline
\end{tabular}

Figura 4 - Modelo de clima e motivação de comportamento organizacional Fonte: LITWIN \& STRINGER, 1968.

O clima organizacional e a motivação, considerando-se, respectivamente, o contexto da organização e do indivíduo, estão relacionados por um princípio de vasos comunicantes, no qual ambos estão conectados e atuando em um mesmo cenário. Dessa forma, seria possível afirmar que há uma interrelação e que as pressões e que estas são exercidas mutuamente (Bergamini, 2006).

A ideia de interdependência é reforçada por Fischer, Veloso e Nakata (2007), ao afirmarem que há três pressupostos sobre o ambiente de trabalho que raramente os gestores questionariam: (1) pessoas criam e "navegam" por significados - o trabalho em grupo cria um conjunto de percepções que o indivíduo assume como verdades; (2) significados comuns são orientadores de comportamento - ao assumir como verdades opiniões e percepções diversas, o comportamento dos indivíduos e suas decisões são orientados de acordo com o discurso coletivo; (3) o contexto interfere no desempenho da organização - o ambiente organizacional pode tanto ser um patrimônio da empresa quanto um dos restritores do seu sucesso, dependendo da coerência entre a estratégia da organização e suas características. Dessa maneira, os autores afirmam que o clima organizacional reflete um estado momentâneo, sujeito a alterações após uma notícia ou um evento, ou seja, é de caráter transitório e volátil.

O desafio da alta administração, nesse sentido, é compreender esse estado momentâneo, de caráter transitório e volátil, medindo-o de maneira eficaz pela pesquisa de clima organizacional e operacionalizando os seus resultados, afinal esse instrumento oferece a oportunidade de identificar quais necessidades dos funcionários estão ou não sendo atendidas. Além disso, tal compreensão permitirá gerar decisões de intervenção em busca da satisfação das necessidades pessoais dos participantes e da elevação do seu moral (Coda, 1992; Santos, 1999).

Fischer et al. (2007) complementam essa ideia ao afirmarem que a decisão de análise 
e intervenção sobre as várias dimensões da vida organizacional gerou a noção de gestão do clima organizacional. Dessa maneira, a pesquisa acerca de clima organizacional possui um objetivo mais amplo que as medidas de satisfação, envolvendo percepções complexas e reflexivas dos funcionários. Para uma construção metodológica da pesquisa sobre clima organizacional, essas percepções podem ser categorizadas em: (1) identidade; (2) satisfação e motivação; (3) aprendizado e desenvolvimento; e (4) liderança (Fischer et al., 2007).

Essas categorias refletem as experiências vivenciadas pelas pessoas no ambiente de trabalho originadas por oito tipos de relações: (1) pessoa em relação à empresa como instituição; (2) pessoa em relação às diretrizes estratégicas; (3) pessoa em relação ao caráter do negócio; (4) pessoa em relação à empresa como empregadora; (5) pessoa em relação aos gestores; (6) pessoa em relação a outras pessoas; (7) pessoa em relação aos processos de gestão; e (8) pessoa em relação ao processo e à organização do trabalho (Fischer et al., 2007). A Figura 5 representa esse modelo de análise.

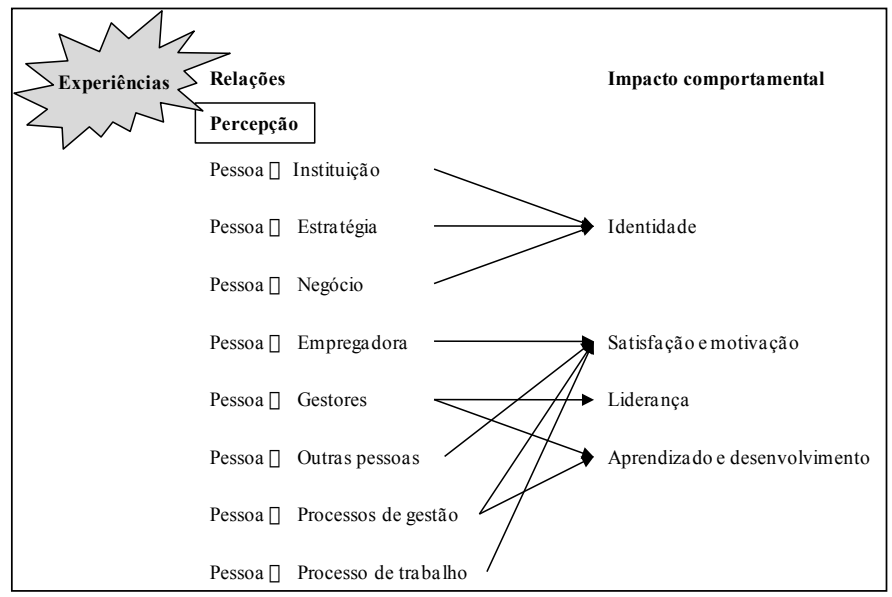

Figura 5 - Impactos comportamentais e origem das categorias de identidade, satisfação e motivação, aprendizado e desenvolvimento, e liderança.

Fonte: Veloso, Nakata, Fischer e Dutra, 2007.

As quatro relações que originam a categoria "Satisfação e Motivação" são definidas como: (1) pessoa em relação à empresa como instituição - predominância da visão mais clássica de clima organizacional, relativa à carreira, à remuneração, a serviços de $\mathrm{RH}$ e a benefícios; (2) pessoa em relação a outras pessoas - questionamento acerca das relações estimulantes e motivadoras com as outras pessoas; (3) pessoa em relação aos processos de gestão - percepção das pessoas quanto ao processo de gestão da empresa, tais como comunicação, decisão, organização etc.; e (4) pessoa em relação ao processo e à organização do trabalho - maneira pela qual as pessoas executam o seu trabalho influencia significativamente sua percepção sobre a empresa (Fischer et al., 2007).

De acordo com Veloso, Nakata, Fischer e Dutra (2007), a categoria de impacto comportamental "Satisfação e Motivação" compreende a satisfação e a motivação em relação àquilo que as pessoas fazem dentro da organização e às recompensas advindas com o dia a dia de trabalho:

[...] os fatores motivacionais diferem daqueles que determinam a satisfação no trabalho. Abordagens mais recentes demonstram como esses fatores dependem das características dos indivíduos e dos grupos aos quais pertencem. De acordo com essa perspectiva diferentes trabalhadores possuem diferentes fatores motivacionais e, além de buscar modos de satisfação distintos, também têm diferentes contribuições a fazer à organização (Veloso et al., 2007, p. 8). 
A próxima seção apresenta algumas teorias motivacionais consagradas e traz um resumo dessa recente discussão sobre motivação do homem para o trabalho.

\subsection{Motivação}

Nos primórdios da Revolução Industrial, a motivação assumia a forma do medo de punição (Casado, 2002). Para o "pai da Administração Científica", Frederick Taylor, bastavam as variáveis ambientais estarem suficientemente controladas que os empregados passariam a produzir mais (Bergamini, 2006). Henri Fayol, fundador da Teoria Clássica, afirmava que a empresa deveria retribuir de forma justa os empregados em termos de remuneração para manutenção da satisfação (Chiavenato, 2004). Nos anos 20, a experiência de Hawthorne, liderada por Elton Mayo, introduziu na administração os primeiros indícios da subjetividade dos trabalhadores, dando origem à Escola das Relações Humanas, que levava em conta fatores afetivos e emocionais (Chiavenato, 2004).

Dentre as teorias motivacionais mais conhecidas, está a Teoria da Hierarquia de Necessidades de Maslow, formulada em 1943. Essa teoria está baseada no pressuposto de que as necessidades humanas podem ser hierarquizadas em cinco níveis: (1) necessidades fisiológicas, (2) necessidades de segurança, (3) necessidades sociais, (4) necessidades de estima e (5) necessidades de autorrealização (Casado, 2002). Pouco se alcançou, no entanto, com sua aplicação prática, já que trabalhadores de níveis socioeconômicos mais baixos tendem a preocupar-se com as necessidades fisiológicas e de segurança, enquanto que trabalhadores de nível socioeconômico mais alto preocupam-se com as necessidades sociais, de estima e de autorrealização. Embora a teoria de Maslow possa explicar esses resultados, não podemos generalizar, pois não obteve validação científica (Casado, 2002).

Os trabalhos de Mayo e Maslow abriram caminho para o desenvolvimento da Teoria X-Teoria Y, formulada por McGregor (Hersey \& Blanchard, 1986). Essa teoria sustenta que os executivos têm duas visões distintas sobre os seus funcionários: uma negativa (Teoria $X$ ) e uma positiva (Teoria Y). Aspectos negativos, como o funcionário não gostar de trabalhar por natureza e não querer assumir responsabilidades, contrastam com aspectos positivos, como demonstração de auto-orientação e autocontrole por parte dos funcionários quando estão comprometidos com os objetivos (Robbins, 2006). Ao analisarem a Teoria X-Teoria Y, Hersey e Blanchard (1986) questionam se o trabalho é mesmo um mal necessário, como preconiza a Teoria-X. Os autores ponderam que, nas empresas em que os objetivos pessoais e organizacionais são contrastantes, as equipes de trabalho são coesas, a produtividade é elevada e as pessoas trabalham felizes, pois ali atingiram uma satisfação intrínseca. $O$ tipo de administrador $Y$ é aquele que busca o amadurecimento dos seus funcionários, procurando satisfazer suas necessidades sociais, de autoestima e de autorrealização através do controle externo cada vez menor (Hersey \& Blanchard, 1986).

Outro teórico importante na área é Herzberg, que começou a trabalhar na sua Teoria dos Dois Fatores em meados de 1950 (Casado, 2002). Para ele, fatores que geram insatisfação não são os mesmos que geram satisfação no trabalho. Fatores como política, administração da empresa, relacionamento com o supervisor e salário, denominados fatores de higiene, não fazem um funcionário motivado. Ao contrário, são apenas capazes de não o desmotivar. Por outro lado, execuções, reconhecimento, o trabalho em si e responsabilidade, denominados fatores de motivação, são capazes de motivar as pessoas (Herzberg, 1997).

Já a Teoria da Expectativa, formulada por Vroom, surgiu em 1964. Para o autor, o homem é possuidor de desejos e crenças e é capaz de atuar antecipadamente sobre os eventos de sua vida, despendendo o esforço necessário na direção certa para atingir os seus objetivos. Nesse 
sentido, o comportamento do homem no trabalho é passível de explicação (Casado, 2002). Na Teoria da Expectativa, a força da tendência para agir de determinada maneira depende da força da expectativa de que esta ação trará certo resultado. A atração que esse resultado exerce sobre o indivíduo influencia suas ações (Robbins, 2006).

Mais recentemente, a motivação vem sendo associada ao sentido que as pessoas atribuem ao trabalho realizado. A motivação só passou a ser um tópico estudado na administração quando o sentido do próprio trabalho desapareceu, devido à sua crescente divisão e fragmentação (Sievers, 1990). O desafio dos gestores é, então, entender o sentido que cada um atribui ao trabalho realizado (Bergamini, 2003). Todo dinheiro gasto para tentar motivar os empregados seria poupado se os administradores evitassem desmotivá-los, pois as pessoas já vêm motivadas para o trabalho. $O$ caminho da desmotivação é traçado pela negligência e falta de consideração do administrador. Inicialmente, o empregado fica confuso, o que o leva à irritação e à esperança subconsciente. Isso o conduz à desilusão e, daí, à falta de cooperação. Quando chega no nível da desmotivação, o empregado deixa a empresa ou se acomoda a um padrão mínimo de trabalho, que resulta na queda de produtividade (Meyer, 1977 como citado em Bergamini, 2003).

Uma solução para evitar a rota da desmotivação é "empoderar" as pessoas. Isso significa criar condições para sustentação do tripé formado pelo conhecimento, pela experiência e pela motivação. Não é possível criar comprometimento na equipe quando todas as decisões são concentradas no topo da hierarquia. Porém, o grande equívoco do empoderamento é o gerente "dar o poder" às pessoas, pois, dessa maneira, ele continua a controlar a situação. A chave da questão é liberar o poder inerente às pessoas (Randolph \& Blanchard, 2007). A liderança inspiracional, competência que libera a motivação que os liderados já trazem dentro de si, seria capaz de despertar nas pessoas os mais altos níveis de motivação, ao contrário das práticas burocráticas de comando e imposição (Bergamini, 2003).

Nesse sentido, Levy-Leboyer (1974 como citado em Bergamini, 2006) sustenta que a motivação para o trabalho é um fenômeno que se manifesta pelo conjunto da situação, ou seja, o indivíduo, o trabalho e a organização, com suas regras, seus objetivos e seus climas próprios. Albuquerque (2002) defende a integração da estratégia de gestão de pessoas à estratégia organizacional. Para o autor, a administração estratégica é definida como um processo que abrange a visão, a formulação, a implementação, o feedback e a avaliação dos resultados, que devem orientar as ações organizacionais nos níveis estratégico, tático e operacional. Dessa maneira, as estratégias corporativas e de recursos humanos são influenciadas pelo ambiente organizacional, segundo Albuquerque (2002). Esse autor ainda ressalta a importância de analisar as tendências de mudanças no ambiente econômico, tecnológico, social, cultural e político para a formulação das respectivas estratégias corporativa.

\subsection{Gestão na era da turbulência econômica}

A gestão de pessoas e negócios é influenciada por fatores sociais, políticos e econômicos, como observado na evolução das teorias motivacionais apresentadas no capítulo anterior. Recentemente, observou-se um novo movimento, quando o mundo entrou em uma nova era econômica graças à difusão de informações pela internet e por telefones celulares. A economia global tornou-se, então, estreitamente interdependente, gerando um novo nível de fragilidade. Prova disso foi o colapso provocado em diversas economias ao redor do mundo pela turbulência no mercado financeiro dos Estados Unidos no final de 2008. Essa turbulência deve ser encarada como o estado normal, pois o caos, o risco e a incerteza formam a nova normalidade, que contrasta períodos in- 
termitentes de aceleração e desaceleração econômica. Em decorrência disso, as empresas deverão detectar as mudanças e reagir com mais rapidez a elas, pois a turbulência intensa e imprevisível é a característica do mundo cada vez mais globalizado (Kotler \& Caslione, 2009).

O efeito em escala global da retração econômica demandará maiores desafios de gestão. Os líderes terão de promover mudanças na forma de administração, pois a volatilidade do ambiente requer frequentes ajustes no nível operacional, além de ocasionais disrupções. Essas condições requerem um tipo diferente de liderança, preparada para promover mudanças estratégicas, estruturais, financeiras e operacionais (Charan, 2009). Muitos líderes, no entanto, sentem-se culpados ao promoverem cortes de despesas, pois prever os efeitos dessas decisões nem sempre é fácil. A tomada de decisões rápidas e ousadas pressupõe líderes ousados e decididos, capazes de manter a união e a motivação das suas equipes (Kotler \& Caslione, 2009).

Conservar o moral dos empregados responsáveis pela fabricação e pelas operações elevado é de fundamental importância nesse processo para manutenção da produtividade e do clima de otimismo. O principal foco é garantir que o fluxo de informações negativas recebidas pelos funcionários através de jornais, televisão e internet seja revertido em comunicações precisas e atualizadas sobre as ações da empresa para sobreviver e prosperar no ambiente turbulento. Uma comunicação contínua garante a assimilação da mensagem, que deve ser consistente a todos os públicos. Comunicar aos empregados as ações tomadas para superação da crise, algumas delas dolorosas, e ao mesmo tempo revelar a verdade sobre o ambiente econômico requer argumentos convincentes, que gerem confiança no processo de superação dos problemas enfrentados e de fortalecimento da empresa (Charan, 2009; Kotler \& Caslione, 2009).

Em meio a esse ambiente turbulento, a área de Recursos Humanos (RH) tem um papel fundamental. Pessoas em todos os níveis da organização são afetadas nos primeiros estágios das crises, pois há grandes chances de projetos serem cancelados e empregados serem demitidos, impactando a motivação das pessoas (Charan, 2009). A área de RH deve atuar para minimizar esses impactos e manter o rumo da organização, orientando os gestores de alto nível hierárquico a reconfigurarem seus processos e ajustarem o que estiver errado. Nesse contexto, dez recomendações são feitas à área de RH para ajudar a empresa a avançar quando a economia recua: (1) continue recrutando; (2) não recrute problemas; (3) distribua seus recursos com sabedoria; (4) continue conversando; (5) não se limite apenas às mensagens do Chief Executive Office CEO; (6) entreveja os raios de sol por trás das nuvens escuras; (7) continue treinando o pessoal; (8) arregimente a equipe para consertar o que estiver quebrado; (9) acompanhe; e (10) mantenha em movimento os melhores operadores (Kotler \& Caslione, 2009).

Essas recomendações visam amenizar o impacto negativo nos resultados financeiros, caso as difíceis decisões tomadas pelas empresas nos tempos de turbulência minem a confiança dos empregados, além da cultura e dos valores da organização (Kotler \& Caslione, 2009). As empresas que se destacam em tempos de mudança preservam firmemente a sua ideologia central. Seus valores solidamente arraigados não são abalados por tendências ou modismos e a vontade de progredir dessas empresas, somado a tudo que não faz parte de sua ideologia central, induz mudanças e um movimento para frente (Collins \& Porras, 1995).

No próximo capítulo, são discutidos os procedimentos metodológicos definidos para este estudo, com o objetivo de responder ao problema e atingir os objetivos apresentados no Capítulo 1. 


\section{METODOLOGIA}

A presente pesquisa caracteriza-se como descritiva. Esse tipo de pesquisa tem o objetivo de familiarização com fenômenos relativamente conhecidos, buscando interpretá-los em contextos particulares. Dessa maneira, o estudo descritivo procura integrar medições ou conceitos, sem o objetivo de indicar como se relacionam as variáveis medidas. Para análise dos dados, adotou-se o modelo de enfoque dominante quantitativo sobre o qualitativo. Nesse modelo, o enfoque quantitativo prevalece, conservando-se os componentes do enfoque qualitativo. A mistura desses dois enfoques contribui para a construção de teorias, a geração de conhecimento e a resolução de problemas. Compreender como o ambiente externo às organizações influencia a motivação dos trabalhadores, objetivo deste estudo, requer a integração de diversos conceitos. Logo, o presente trabalho de pesquisa pretende descrever como se manifesta esse fenômeno (Sampieri, Collado, \& Lucio, 2006).

\subsection{População e Amostra}

A população estudada no presente trabalho de pesquisa é composta pela totalidade dos respondentes (funcionários) das empresas que foram eleitas como uma das 150 melhores para se trabalhar no Brasil em 2007, 2008 e 2009. Para podermos fazer a comparação entre as médias da categoria "Satisfação e Motivação" de 2007 a 2009 de maneira coerente, garantindo a normalização do conjunto dos dados por período, a amostra foi extraída pelo cruzamento das empresas eleitas no período, considerando-se que:

- Das 150 empresas que figuraram no Guia em 2007, 93 também figuraram em 2008.

- Das 93 empresas que figuraram no Guia em 2007 e 2008, 66 também figuraram em 2009.

Portanto, o presente trabalho de pesquisa considera como unidade de estudo as 66 empresas que figuraram no Guia em 2007, 2008 e 2009.

\subsection{Coleta de dados}

Os dados para realização do presente trabalho de pesquisa foram retirados de duas fontes secundárias:

- Base de dados da pesquisa "As 150 Melhores Empresas para Você Trabalhar", administrada pelo Progep-FIA;

- Guia Você S/A-Exame As 150 Melhores Empresas para Você Trabalhar, edições 2007, 2008 e 2009.

\subsection{A pesquisa "As 150 Melhores Empresas para Você Trabalhar"}

A pesquisa que define as 150 melhores empresas para se trabalhar no Brasil é realizada através de uma parceria entre a Fundação Instituto de Administração (FIA) e a revista Você S/A. Os resultados são publicados anualmente através do Guia Você S/A-Exame As 150 Melhores Empresas para Você Trabalhar. Para participar da pesquisa, a empresa deve ter no mínimo 100 empregados e estar operando há mais de cinco anos no mercado brasileiro (FIA, 2009). Em 2008, participaram da 
pesquisa 550 empresas e foram obtidos mais de 140.000 questionários respondidos (FIA, 2009). Em 2009, foram 124.009 respondentes distribuídos em 491 empresas (Veloso, 2009).

A nota final de cada empresa, conhecida como Índice de Felicidade no Trabalho (IFT) é composta por três fatores: (1) o Índice de Qualidade no Ambiente de Trabalho (IQAT), que representa 70\% do IFT, (2) o Índice de Qualidade na Gestão de Pessoas (IQGP), que representa $20 \%$ do IFT e (3) uma nota atribuída pelos jornalistas da Você S/A a cada visita realizada, que representa $10 \%$ do IFT (FIA, 2009).

O questionário para diagnóstico do clima organizacional, que origina o IQAT, é composto por 68 questões, divididas em cinco categorias: (1) identidade; (2) satisfação / motivação; (3) liderança; (4) aprendizado / desenvolvimento; e (5) outras (sem pontuação). O cálculo da pontuação é igual a soma das proporções das respostas 4 e 5 (concordo parcialmente e concordo totalmente) nas afirmativas do questionário (FIA, 2009).

\section{PLANO DE ANÁLISE DE DADOS}

\subsection{Análise Quantitativa}

Os dados da amostra foram submetidos a operações estatísticas para determinar tanto a sua normalidade quanto a igualdade de variâncias. A normalidade é observada através das medidas de assimetria e curtose e da aplicação do teste Kolmogorov-Smirnov (KS). O KS é um teste de aderência, usado para saber o grau de concordância entre a distribuição dos valores observados e uma distribuição teórica especificada (Siegel \& Castellan, 2006). Quanto ao nível de significância das análises, o presente trabalho de pesquisa trabalhou com $5 \%$, o que implica $95 \%$ de segurança para realizar as generalizações.

O próximo passo foi investigar se havia diferença entre as porcentagens médias de respostas "Concordo totalmente" e "Concordo parcialmente" nos três anos analisados. Para isso, utilizou-se o Modelo Linear Geral (General Linear Model - GLM) com medidas repetidas. Esse teste é usado quando as variáveis que estão sendo analisadas não provêm de amostras independentes. Desta forma, as mesmas empresas foram avaliadas três vezes em anos diferentes, o que significa que as observações não foram independentes. O propósito de testes de medidas repetidas é controlar diferenças de nível individual que possam afetar a variância interna dentro do grupo. O método de seleção é o Lambda de Wilks, que considera como critério de seleção de variáveis o valor da Distribuição F Multivariada (Hair, Anderson, Tatham, \& Black, 2007).

As hipóteses testadas foram:

- HO: Não há diferença entre as médias dos três anos (2007, 2008, 2009).

- H1: Há diferença entre as médias de pelo menos dois dos três anos.

Os valores de Lambda de Wilkis e de $\mathrm{F}$ no teste indicam os efeitos principais, mas não revelam quais anos diferem entre si. Para isso, foi realizado o teste post-hoc, que é um teste estatístico entre as médias. Assim sendo, foram testadas as diferenças entre todas as combinações dois a dois possíveis entre os grupos (Hair et al., 2007). Os dados foram analisados pelo programa computacional Statistical Package for the Social Sciences (SPSS) versão 13.0.

\subsection{Análise Qualitativa}

Utilizaram-se, na presente pesquisa, dois métodos de análise qualitativa: análise explo- 
ratória de dados e análise de conteúdo. Uma das técnicas disponíveis para a análise exploratória é a distribuição de frequências (Sampieri et al., 2006). Essa análise exploratória verificou as variações nos índices que compõem o resultado da categoria "Satisfação e Motivação" em 2009. Desse modo, os resultados das 30 afirmativas de 2008 e 2009 foram comparados a fim de observar as possíveis variações presentes.

Dentre as técnicas de análise de conteúdo existentes, optou-se pela análise de enunciação. Nessa técnica, o discurso é tomado como um ato da fala, apoiando-se na concepção de comunicação como processo, sujeito às condições de produção e do rodeio para enunciação. A análise de enunciação busca a compreensão do ponto de vista do entrevistado, bem como de suas referências. $O$ plano de análise de enunciação divide-se em três etapas: (1) codificação inicial, (2) categorização e (3) inferência (Bardin, 2008). A análise de enunciação é utilizada para identificar no discurso dos funcionários elementos que evidenciem as ações tomadas pelas empresas perante a crise econômica mundial em 2009 para mantê-los motivados.

A codificação inicial consiste na leitura superficial dos artigos escritos pelos jornalistas da Você/SA sobre as visitas realizadas às empresas pertencentes à amostra. Essa leitura tem o objetivo de identificar em quais artigos foram feitas menções à crise econômica mundial que irrompeu no final de 2008. A categorização classifica os elementos de acordo com o que cada um deles tem em comum com outros, permitindo um agrupamento (Bardin, 2008). No presente trabalho de pesquisa, foram definidos três conjuntos de categorias: (1) atuação da liderança ações tomadas pelos líderes das empresas a fim de conter os efeitos da crise; (2) comunicação - comunicação formal da empresa com os funcionários a fim de mantê-los informados sobre as ações tomadas em decorrência da crise; (3) manutenção do moral da equipe - ações da empresa ou da liderança a fim de manter o moral da equipe elevado durante o período de crise. Na última etapa, as inferências foram realizadas de acordo com a análise do discurso como processo, com o objetivo de responder aos critérios de interpretação, de sistematização e de generalização das ações tomadas pelas empresas (Bardin, 2008).

\section{ANÁLISE DOS RESULTADOS}

Nesta seção, são realizadas as análises dos dados obtidos durante a pesquisa e a descrição dos resultados, a fim de atingir os objetivos inicialmente propostos no Capítulo 1.

\subsection{Análise quantitativa}

Inicialmente, adotou-se a análise da estatística descritiva dos dados. Os valores da variância foram próximos $\left(\sigma_{2007}^{2}=0,0032 ; \sigma_{2008}^{2}=0,0028 ; \sigma_{2009}^{2}=0,0028\right)$, o que permite a realização de teste de hipótese paramétrico. Os valores de assimetria $\left(G_{2007}=0,121 ; G_{2008}=0,396 ; G_{2009}=\right.$ $0,440)$ e curtose $\left(K_{2007}=-0,935 ; K_{2008}=-0,282 ; K_{2009}=-0,439\right)$ foram próximos de zero, indicando que, provavelmente, as amostras têm distribuição normal. Testada essa hipótese através do teste $K S$, os resultados indicaram: $p_{2007}=0,693 ; p_{2008}=0,784 ; p_{2009}=0,648$. Como todos os resultados foram superiores a 0,05 , aceita-se a hipótese nula, ou seja, de que os dados seguem a distribuição normal, o que permite a realização de teste de hipótese paramétrico.

O GLM mostrou que houve diferença significativa entre as médias dos três anos, já que $p<0,05$ :

Lambda de Wilks: 0,800, $F(2,64)=8,00, p=0,001, P O=0,948$ 
Portanto, rejeita-se a hipótese $\mathrm{HO}$ e aceita-se a hipótese $\mathrm{H} 1$ : há diferença entre as médias da categoria "Satisfação e Motivação" ao longo do período analisado. $O$ alto poder do teste $(P O=0,948)$ indica que há uma probabilidade de $94,8 \%$ de identificar o efeito na amostra, se ele realmente existir. Ele é definido como 1 - $\beta$, onde $\beta$ corresponde ao erro tipo II (não rejeitar a hipótese nula em uma situação em que ela deveria ser rejeitada, ou seja, dizer que as médias dos grupos não diferem entre si, quando, na realidade, diferem).

Para conclusão da análise quantitativa, aplicou-se o teste post-hoc LSD aos resultados dos três anos a fim de determinar como se deu essa variação. Os resultados do post-hoc LSD foram: $p_{2007-2008}=0,547 ; p_{2007-2009}=0,030 ; p_{2008-2009}<0,001$. Isso significa que, com 95\% de confiança, as médias de 2007 e 2008 não diferiram significativamente $(p>0,05)$. Já a média de 2009 diferiu significativamente das médias de $2007(p<0,05)$ e $2008(p<0,05)$.

Dessa maneira, atingem-se o objetivo geral e o primeiro objetivo específico propostos. As análises permitem responder com $95 \%$ de confiança ao problema de pesquisa, ou seja, rejeitase a hipótese de que não houve diferença significativa nas médias e aceita-se a hipótese de que houve diferença nas médias ao longo do período analisado. A média de 2009 diferiu significativamente das médias de 2007 e 2008. Como as variâncias dos três anos são praticamente iguais, pode-se concluir que houve similaridade entre os respondentes das pesquisas nos três anos. Embora seja pouco provável que as mesmas pessoas tenham respondido aos questionários nos três anos consecutivos, é possível afirmar que o clima percebido pelos funcionários da empresa variou de maneira uniforme. Deve-se, então, investigar as causas da queda apresentada em 2009.

Embora exista diferença entre as médias da categoria "Satisfação e Motivação" de 2009 em relação a 2007 e 2008, isso não permitiria inferir que a causa foi a crise econômica mundial, pois a hipótese não expressa essa relação de causalidade. Dessa maneira, não se pode afirmar, categoricamente, que a crise econômica mundial impactou a motivação dos trabalhadores. Porém, de acordo com a revisão teórica, é possível afirmar que essa é uma variável que atinge, em maior ou menor grau, todas as empresas e os segmentos, sendo esta uma variável a que as organizações, invariavelmente, estiveram sujeitas. A seguir, observam-se, pela análise qualitativa, aspectos que corroboram tal inferência.

\subsection{Análise qualitativa}

A análise qualitativa dos dados, expostos na Tabela 1, mostrou que, entre 2007 e 2008, $60 \%$ das afirmativas que compõem a categoria "Satisfação e Motivação" tiveram variação positiva. Esse índice caiu para apenas 7\% entre 2008 e 2009.

Tabela 1 - Variações positivas e negativas nos resultados das afirmativas

\begin{tabular}{l|c|c|c|c}
\hline \multirow{2}{*}{ Variação } & \multicolumn{2}{|c|}{$\mathbf{2 0 0 7 / 2 0 0 8}$} & \multicolumn{2}{c}{$\mathbf{2 0 0 8 / 2 0 0 9}$} \\
\cline { 2 - 5 } & Absoluta & Relativa & Absoluta & Relativa \\
\hline Positiva & 18 & $60 \%$ & 2 & $7 \%$ \\
\hline Nula & 1 & $3 \%$ & 0 & $0 \%$ \\
\hline Negativa & 11 & $37 \%$ & 28 & $93 \%$ \\
\hline Total & 30 & $100 \%$ & 30 & $100 \%$ \\
\hline
\end{tabular}

Fonte: Elaborado pelos autores (2012).

O ambiente externo às organizações pode influenciar a motivação despertada nos funcionários (Litwin \& Stringer, 1968 como citado em Nardi, 2004). Dessa maneira, a crise econômica mundial, deflagrada no final de 2008 (Bacen, 2009), pode ter influenciado os resultados da 
pesquisa de clima organizacional. Para melhor entender esse fenômeno, é importante relacionar o período em que as pesquisas foram realizadas com o momento econômico sob o enfoque da revisão teórica apresentada.

Os questionários foram respondidos entre fevereiro e maio de 2009. Esse período foi marcado pelo agravamento da crise, conforme se pôde observar pela queda acentuada no nível da atividade econômica (Figura 1) e no nível de contratações no mercado formal (Figura 2). Nesse ponto, é importante ressaltar as características de transitoriedade e de volatilidade do clima organizacional (Fischer et al., 2007), já que esse período foi marcado por uma série de notícias ruins no campo econômico (Kotler \& Caslione, 2009).

O clima organizacional é favorável quando proporciona satisfação às necessidades pessoais dos participantes e elevação do moral dos funcionários (Coda, 1992; Santos, 1999). Em épocas de turbulência econômica, é importante manter o moral dos funcionários elevado (Charan, 2009; Kotler \& Caslione, 2009), pois, conforme o princípio de vasos comunicantes,, os possíveis impactos da crise econômica são sentidos tanto pela empresa quanto pelos funcionários (Bergamini, 2006).

A Tabela 2 mostra quais foram as cinco afirmativas na pesquisa que tiveram a maior variação negativa de 2008 para 2009 e as duas afirmativas que tiveram variação positiva de 2008 para 2009. Essas sete afirmativas serão chamadas de pontos de atenção.

Tabela 2 - Pontos de Atenção

\begin{tabular}{|c|c|c|c|}
\hline Afirmativa & 2008 & 2009 & Variação \\
\hline Recebo todas as informações que preciso para fazer bem o meu trabalho & $85,59 \%$ & $82,28 \%$ & $-3,31 \%$ \\
\hline $\begin{array}{l}\text { Nesta empresa as pessoas estão sempre dispostas a ajudar umas às ou- } \\
\text { tras }\end{array}$ & $77,18 \%$ & $74,35 \%$ & $-2,83 \%$ \\
\hline $\begin{array}{l}\text { Esta empresa ouve e coloca em prática as sugestões de seus funcioná- } \\
\text { rios }\end{array}$ & $81,35 \%$ & $78,74 \%$ & $-2,61 \%$ \\
\hline $\begin{array}{l}\text { As pessoas que trabalham nesta empresa se dão muito bem umas com } \\
\text { as outras }\end{array}$ & $80,72 \%$ & $78,65 \%$ & $-2,07 \%$ \\
\hline Sou reconhecido e recompensado quando realizo um bom trabalho & $76,53 \%$ & $74,51 \%$ & $-2,02 \%$ \\
\hline A quantia que recebo como participação nos lucros da empresa é justa & $69,06 \%$ & $70,33 \%$ & $1,27 \%$ \\
\hline Sinto que na empresa todos trabalham como um verdadeiro time & $80,96 \%$ & $84,12 \%$ & $3,16 \%$ \\
\hline
\end{tabular}

Fonte: Elaborado pelos autores (2012).

Esses pontos de atenção podem ser relacionados com a teoria motivacional descrita no referencial teórico. Tais pontos relacionam-se, inicialmente, com a análise crítica das cinco afirmativas que apresentaram maior queda. A análise inicial conduz às quatro relações propostas por Fischer et al. (2007) (Figura 5), conforme demonstrado na Figura 6.

\begin{tabular}{|l|l|}
\hline Relação & Pontos de Atenção \\
\hline Pessoa $®$ empresa como empregadora & $\begin{array}{l}\text { Sou reconhecido e recompensado quando realizo um } \\
\text { bom trabalho }\end{array}$ \\
\hline Pessoa $®$ outras pessoas & $\begin{array}{l}\text { Nesta empresa as pessoas estão sempre dispostas a aju- } \\
\text { dar umas às outras } \\
\text { As pessoas que trabalham nesta empresa se dão muito } \\
\text { bem umas com as outras }\end{array}$ \\
\hline Pessoa $®$ processos de gestão & $\begin{array}{l}\text { Esta empresa ouve e coloca em prática as sugestões de } \\
\text { seus funcionários }\end{array}$ \\
\hline $\begin{array}{l}\text { Pessoa } ® \text { processos e organização do traba- } \\
\text { Iho }\end{array}$ & $\begin{array}{l}\text { Recebo todas as informações que preciso para fazer bem } \\
\text { o meu trabalho }\end{array}$ \\
\hline
\end{tabular}

Figura 6 - Experiências X Relações X Impacto Comportamental: Satisfação e Motivação

Fonte: Elaborado pelos autores (2012). 
O modelo proposto por Fischer et al. (2007) mostra-se aplicável na prática, pois foi possível classificar pelo menos uma afirmativa em cada Relação/Percepção geradora da categoria "Satisfação e Motivação". Dessa maneira, pode-se afirmar que a empresa deve estar atenta a todas as relações das pessoas dentro da empresa em épocas de turbulência econômica, pois distorções indesejáveis poderão surgir e afetar negativamente o nível de satisfação dos funcionários (Coda, 1992; Santos, 1999). A pesquisa de clima organizacional fornece informações importantes para que a alta administração possa traçar um plano de ação, alinhado com a estratégia de RH da empresa (Albuquerque, 2002; Fischer et al., 2007). Devem-se observar, nesse ponto, as dez recomendações feitas por Kotler e Caslione (2009) à área de RH que ajudam a empresa a avançar quando a economia recua.

Ao analisar os pontos de atenção que variaram negativamente sob o enfoque da Teoria dos Dois Fatores de Herzberg, foi possível classificar dois pontos como fatores de higiene: (1) "nesta empresa as pessoas estão sempre dispostas a ajudar umas às outras" e (2) "as pessoas que trabalham nesta empresa se dão muito bem umas com as outras". O não atendimento a esses dois fatores de higiene, de acordo com Herzberg (1997), pode colocar os funcionários na rota da desmotivação, conforme propõe Meyer (1977). Os gestores devem estar atentos a essa questão. Uma teoria que suporta essa ação é a Teoria X-Teoria-Y proposta por McGregor, pois parece ter espaço para ser aplicada nessa situação. $O$ gestor $Y$, conforme sustentam Hersey e Blanchard (1986) a respeito dessa teoria, busca o amadurecimento dos seus funcionários, procurando satisfazer seus fatores de higiene, atuando fortemente nos fatores de motivação. Da mesma maneira, o fator de higiene "a quantia que recebo como participação nos lucros da empresa é justa", embora tenha variado positivamente, não é capaz de motivar as pessoas, de acordo com Herzberg (1997).

A Teoria da Expectativa, proposta por Vroom, está presente em um dos pontos de atenção: "sou reconhecido e recompensado quando realizo um bom trabalho". De acordo com essa teoria, as pessoas esforçam-se para atingir um determinado resultado para a organização quando esperam que o seu esforço individual atenda às suas metas pessoais.

É importante ressaltar que os teóricos contemporâneos sustentam que a mera transcrição dessas teorias clássicas para a prática mostrara-se ineficiente ao longo do tempo. É primordial que os líderes assumam os papéis indicados por Meyer (1977), Bergamini (2003) e Randolph e Blanchard (2007). Esses autores propõem que os gestores devem libertar as potencialidades dos seus liderados, pois somente assim estes atingirão a verdadeira motivação intrínseca. Conforme mostrado na Tabela 2, é o que pareceu acontecer, em certa medida, com o salto de 3,16\% do índice "sinto que na empresa todos trabalham como um verdadeiro time".

Dessa maneira, atinge-se o segundo objetivo específico de verificar as variações nos índices que compõem o resultado da categoria "Satisfação e Motivação" da Pesquisa de Clima Organizacional das Melhores Empresas para se Trabalhar no Brasil em 2009 e relacionar tais variações com a teoria motivacional.

\subsubsection{Análise de enunciação}

Durante a codificação inicial dos dados, a palavra "crise" foi encontrada em 12 dos 66 artigos analisados no Guia em 2009. As afirmações dos funcionários, decorrentes das ações tomadas pelas empresas perante a crise econômica mundial, foram classificadas nas três categorias propostas: (1) atuação da liderança; (2) manutenção do moral; e (3) comunicação.

Conforme propõe Charan (2009, p. 107), "Pessoas indecisas ou temerosas não têm lugar 
em uma organização que precisa tomar decisões rápidas e ousadas, motivar e incentivar as pessoas a agir como uma equipe unida." Ao despertarem sensação de trabalho em equipe, os líderes parecem ter assumido um papel importante na gestão de pessoas no período de turbulência econômica. A análise das afirmações a seguir demonstra a atuação da liderança no momento de crise:

- "O diretor pediu nossa colaboração para economizar. Nós demos um voto de confiança à empresa";

- "Essa foi uma prova de confiança na liderança da empresa. Até o sindicato defendeu";

- "Enquanto nós pensávamos que nem receberíamos a PLR, o presidente estava inseguro com o valor, que considerou baixo";

- "Não há mais espaço para a improvisação. Tudo tem que ser previsto".

Conforme descrito anteriormente, a manutenção do moral dos funcionários é muito importante durante os momentos de crise. Ao que parece, as empresas aplicaram as ideias propostas por Charan (2009) e Kotler e Caslione (2009), evidenciadas pelas seguintes afirmativas dos trabalhadores:

- "Está vendo aquele jardim lá fora? Fomos nós que arrumamos";

- "Também recebemos treinamento para outras funções. Não houve reclamação porque ninguém quer sair daqui";

- "Sabemos que aqui o foco é o funcionário";

- "A empresa deu todo o apoio aos que saíram";

- "Muita gente foi trabalhar em parceiros nossos, como lojistas e prestadores de serviço";

- "A empresa se manteve forte e cresceu na crise";

- "Muitas empresas aqui em (local) mandaram gente embora ou os funcionários entraram em greve. Aqui, isso dificilmente vai acontecer porque nós somos valorizados";

- "A produção caiu, não tinha o que fazer, mas não fomos demitidos";

- "Saber que a empresa não deixa de investir nas pessoas mesmo em uma situação de contingência fortalece a equipe";

- "Aqui a gente tem o respaldo que precisa para fazer um bom trabalho".

Quanto à comunicação clara sobre o rumo das empresas durante a crise, é possível evidenciar as ações das empresas através das seguintes afirmações:

- "Foram criteriosos" (sobre as demissões);

- "Temos certeza de que a empresa está fazendo o que pode para manter os empregos, o que faz com que estejamos prontos para ajudar";

- "Isso deu tranqüilidade" (sobre o discurso do CEO);

- "Fomos comunicados, mas já sabíamos que a estrutura estava inchada para aquele momento".

Essas evidências coletadas através das afirmações dos funcionários permitem cumprir o terceiro objetivo específico de identificar, no discurso dos funcionários das Melhores Empresas para se Trabalhar no Brasil, elementos que evidenciem as ações tomadas pelas empresas perante a crise econômica mundial em 2009 para mantê-los motivados e relacionar tais ações com a teoria sobre gestão na era da turbulência econômica. 


\section{CONCLUSÃO}

O presente trabalho de pesquisa teve por objetivo identificar diferenças significativas nos níveis de "Satisfação e Motivação" dos funcionários das Melhores Empresas para se Trabalhar no Brasil entre 2007 e 2009. A seguir, apresentam-se os aspectos mais importantes da pesquisa, as contribuições práticas, as limitações do trabalho e a sugestão para estudos futuros.

\subsection{Aspectos mais importantes da pesquisa}

Relacionar diversos conceitos buscando estabelecer uma comunicação entre a motivação do homem para o trabalho com o ambiente econômico foi um grande desafio para os autores deste estudo. Conforme contextualizado no capítulo introdutório, muitas questões envolvendo capital e trabalho permanecem sem resposta. A presente pesquisa pretendia dar sua contribuição ao tema, sem, no entanto, enveredar pela discussão ideológica socialismo/capitalismo, a fim de poder contribuir para a prática da Administração de Empresas. Para isso, o caminho seguido foi descrever de que maneira o nível de "Satisfação e Motivação" dos trabalhadores das empresas que figuraram no Guia As Melhores Empresas para Você Trabalhar variou no período de 2007 a 2009.

A principal descoberta deste estudo ocorreu quando se aceitou a hipótese de que houve significativa variação negativa no resultado de 2009 em relação a 2007 e 2008, através da aplicação de métodos estatísticos clássicos. Nesse momento, abriu-se um campo para investigar os possíveis motivos para tal fenômeno. Baseado no contexto econômico dos anos de 2007 a 2009, o presente estudo procurou respostas através da análise qualitativa, embasado pela teoria apresentada, a fim de verificar a possível influência da crise econômica mundial sobre essa descoberta. Afinal, a crise, em maior ou menor grau, afetou todas as empresas e segmentos, como pode ser observado através da brusca queda do PIB do Brasil a partir do quarto trimestre de 2008.

A análise de enunciação realizada permitiu detectar através do discurso dos funcionários elementos que evidenciassem as ações tomadas pelas empresas com o objetivo de mantê -los motivados. Diversas afirmações foram classificadas nas três categorias propostas: (1) atuação da liderança; (2) comunicação; e (3) manutenção do moral da equipe. Embora as melhores empresas para se trabalhar sejam reconhecidamente empresas que aplicam boas práticas de Gestão de Pessoas, elas podem não ter passado imunes ao período de agravamento da crise, que coincidiu, justamente, com o período em que os funcionários responderam aos questionários.

Outro aspecto que pode ser observado nesse sentido é a redução no número de empresas que se inscreveram no processo de classificação em 2009: 491 empresas ante as 550 em 2008. Esse indicador pode demonstrar que as empresas não se inscreverem nesse processo, pois sabiam que talvez não fosse o melhor momento para submeter os seus funcionários a uma pesquisa de clima organizacional, de caráter transitório e volátil, conforme visto no referencial teórico.

Cabe ainda fazer um paralelo do perfil das Melhores Empresas para se Trabalhar com a pesquisa de Collins e Porras (1995) e a declaração de Fischer (GUIA..., 2009, p. 18), a qual afirma que, "Ao preservar crenças e valores, essas empresas ultrapassaram a crise sem impactar a confiança do trabalhador, mesmo tomando medidas desagradáveis". Muito embora as empresas tenham tomado algumas medidas propostas por Kotler e Caslione (2009) e Charan (2009), conforme demonstrado pela análise qualitativa, os resultados quantitativos mostram a queda no nível de "Satisfação e Motivação" em 2009. 


\subsection{Contribuições da pesquisa}

O presente trabalho de pesquisa pretende dar a sua contribuição prática à comunidade de Recursos Humanos sob a perspectiva de quais ações empreender frente aos cinco pontos de atenção verificados pela análise exploratória dos dados, embasada na revisão teórica sobre o tema motivação apresentada. São aspectos que não podem ser esquecidos mesmo em épocas de turbulência econômica:

- Recebo todas as informações que preciso para fazer bem o meu trabalho: o ponto que apresentou maior variação negativa é, talvez, um dos mais importantes para as empresas, afinal, arregimentar as pessoas em torno dos objetivos corporativos cada vez mais exigentes é o papel dos líderes. Selecionar as pessoas certas ou desenvolver aquelas que já estão ocupando essas posições é papel importante do setor de RH.

- Nesta empresa as pessoas estão sempre dispostas a ajudar umas às outras / As pessoas que trabalham nesta empresa se dão muito bem umas com as outras: o clima de camaradagem entre os funcionários é objeto de pesquisa desde a experiência de Hawthorne. $\mathrm{O}$ setor de RH deve estar atento à competição interna exacerbada, fomentada pela alcance de metas algumas vezes dicotômicas dentro da própria empresa.

- Esta empresa ouve e coloca em prática as sugestões de seus funcionários: o motivo de participação das pessoas naquilo que executam traz satisfação intrínseca. A descentralização das decisões representa uma alternativa viável.

- Sou reconhecido e recompensado quando realizo um bom trabalho: as pessoas querem ser reconhecidas e prestigiadas pelo trabalho que realizam. A simples troca do trabalho pelo salário parece não ser mais suficiente hoje em dia. $\mathrm{O}$ setor de $\mathrm{RH}$ deve sempre levantar a bandeira do reconhecimento às realizações dos funcionários. Esse é um fator de motivação intrínseco.

\subsection{Limitações do trabalho e sugestão para estudos futuros}

Quanto às limitações da pesquisa, pode-se citar a impossibilidade de garantir que a causa da queda no nível de "Satisfação e Motivação" em 2009 foi a crise econômica mundial. Sugerem-se estudos futuros com este fim específico, ou seja, estudos causais para validar a crise como variável independente nesse fenômeno.

Outra sugestão para estudos futuros é investigar o estilo de liderança adotado diante da crise, o que pode ter interferido na queda do nível de "Satisfação e Motivação" nas organizações pesquisadas. Sugere-se, ainda, investigar se o recorte setorial explica a queda nos níveis de "Satisfação e Motivação", pois, como citado por Veloso et al. (2007), os fatores motivacionais dependem das características dos indivíduos e dos grupos aos quais pertencem. 


\section{REFERÊNCIAS}

Albuquerque, L. G. (2002). A gestão estratégica de pessoas. In M. T. L. Fleury (Org.). As pessoas na organização. (pp. 35-50) São Paulo: Editora Gente.

Banco Central do Brasil. (2009). Relatório anual 2008. Recuperado em 28 abril, 2010, de http:// www.bcb.gov.br/pec/boletim/banual2008/ rel2008p.pdf

Bardin, L. (2008). Análise de conteúdo. Lisboa: Edições 70.

Bergamini, C. W. (2003). Motivação: uma viagem ao centro do conceito. RAE executivo, $1(2), 63-67$.

Bergamini, C. W. (2006). Psicologia aplicada à administração de empresas: psicologia do comportamento organizacional. (4a ed.). São Paulo: Atlas.

Cadastro Geral de Empregados e Desempregados. Evolução de Emprego do CAGED - EEC. Recuperado em 28 abril, 2010, de http://estatistica.caged.gov.br

Casado, T. (2002). A motivação e o trabalho. In M. T. L. Fleury (Org.). As pessoas na organização. (pp. 247-258) São Paulo: Editora Gente.

Charan, R. (2009). Liderança na era da turbulência econômica: as novas regras de gestão em tempos de economia estagnada. Rio de Janeiro: Elsevier.

Chiavenato, I. (2004). Introdução à teoria geral da administração: uma visão abrangente da moderna administração das organizações. (7a ed.). Rio de Janeiro: Campus.

Coda, R. (1992). Pesquisa de clima organizacional: uma contribuição metodológica. Tese de livre-docência. Universidade de São Paulo, São Paulo, SP, Brasil.
Collins, J. C. \& Porras, J. I. (1995). Feitas para durar: práticas bem-sucedidas de empresas visionárias. Rio de Janeiro: Rocco.

Fischer, A. L., Veloso, E. F. R., \& Nakata, L. (2007). As armadilhas da gestão do conhecimento: o que diferenciam as organizações que se destacam pelo ambiente de trabalho? Revista T\&D Inteligência Corporativa, (152), 58-62.

FUNDAÇÃO INSTITUTO DE ADMINISTRAÇÃO. Laudo Técnico: Pesquisa Você S/A - 2009. Recuperado em 28 abril, 2010, de

http://www.fia.com.br/portalfia/ Repositorio/13/Laudo_tecnico_2009.pdf

Gaulejac, V. (2007). Gestão como doença social: ideologia, poder gerencialista e fragmentação social. São Paulo: Idéias \& Letras.

Gorz, A. (2007). Metamorfoses do trabalho: crítica da razão econômica. São Paulo: Annablume.

GUIA Você S/A-Exame: As melhores empresas para você trabalhar. Edição especial 2007.

GUIA Você S/A-Exame: As melhores empresas para você trabalhar. Edição especial 2008

GUIA Você S/A-Exame: As melhores empresas para você trabalhar. Edição especial 2009.

Hair, J. F., Anderson, R. E., Tatham, R. L., \& Black, W. C. (2007). Análise multivariada de dados. (5a ed.). Porto Alegre: Bookman.

Hersey, P. \& Blanchard, K. H. (1986). Psicologia para administradores: a teoria e as técnicas da liderança situacional. São Paulo: EPU.

Herzberg, F. Mais uma vez: como motivar seus funcionários (1997). In V. H. Vroom (Org.). Gestão de pessoas, não de pessoal. Rio do Janeiro: Elsevier.

Instituto Brasileiro de Geografia e Estatística. Publicações das Contas Nacionais Trimestrais. Recuperado em 28 abril, 2010, de

$\mathrm{ftp}: / / f t p . i b g e . g o v . b r / C o n t a s \_N a c i o n a i s / C o n t a s$ Nacionais_Trimestrais/Fasciculo_Indicadores_IBGE/ 
Kotler, P. \& Caslione, J. A. (2009). Vencer no caos. Rio de Janeiro: Elsevier.

Nardi, A. (2004). Clima organizacional: uma revisão do conceito, instrumentos e dimensões no Brasil e nos EUA. Dissertação de mestrado. Universidade de São Paulo, São Paulo, SP, Brasil.

Randolph, A. \& Blanchard, K. (2007). O empoderamento é a chave. In K. Blanchard (Org.). Liderança de alto nível. (pp 87-107). Porto Alegre: Bookman.

Robbins, S. P. (2006). Comportamento organizacional. (11a ed.). São Paulo: Pearson Prentice Hall.

Sampieri, R. H., Collado, C. F., \& Lucio, P. B. (2006). Metodologia de pesquisa. (3a ed.). São Paulo: McGraw-Hill.

Santos, N. M. B. F. (1999). Clima organizacional: pesquisa e diagnóstico. São Paulo: Stiliano.

Siegel, S. \& Castellan, N. J., Jr. (2006). Estatística não paramétrica para ciências do comportamento. (2a ed.). Porto Alegre: Artmed.

Sievers, B. (1990). Além do sucedâneo da motivação. Revista de administração de empresas, 30(1), 5-16.

Veloso, E. F. R. Clima organizacional e casos de gestão de carreira. Apresentação de slides. Aula ministrada em 14/09/2009 no Curso de Pós-Graduação Lato Sensu Especialização em Modelos de Gestão Estratégica de Pessoas Turma 4 da Fundação Instituto de Administração.

Veloso, E. F. R., Nakata, L. E., Fischer, A. L., \& Dutra, J. S. (2007, setembro). Pesquisas de clima organizacional: o uso de categorias na construção metodológica e análise de resultados. Anais do Encontro Nacional da Associação Nacional de Pós-Graduação e Pesquisa em Administração, Rio de Janeiro, RJ, Brasil, 31. 